\title{
Color record in self-monitoring of blood glucose improves glycemic control by better self-management.
}

\section{AUTHOR(S):}

Nishimura, Akiko; Harashima, Shin-Ichi; Honda, Ikumi; Shimizu, Yoshiyuki; Harada, Norio; Nagashima, Kazuaki; Hamasaki, Akihiro; Hosoda, Kiminori; Inagaki, Nobuya

\section{CITATION:}

Nishimura, Akiko ...[et al]. Color record in self-monitoring of blood glucose improves glycemic control by better self-management.. Diabetes technology \& therapeutics 2014 , 16(7): 447-453

\section{ISSUE DATE:}

2014-07

URL:

http://hdl.handle.net/2433/189100

\section{RIGHT:}

This is a copy of an article published in the Diabetes Technology \& Therapeutics (c) 2014 copyright Mary Ann Liebert, Inc.;'Diabetes Technology \& Therapeutics' is available online at: http://online.liebertpub.com. 


\title{
Color Record in Self-Monitoring of Blood Glucose Improves Glycemic Control by Better Self-Management
}

\author{
Akiko Nishimura, MSN, Shin-ichi Harashima, MD, PhD, Ikumi Honda, $\mathrm{PhD}_{1}^{1,3}$ \\ Yoshiyuki Shimizu, MSN, Norio Harada, MD, PhD, Kazuaki Nagashima, MD, PhD, \\ Akihiro Hamasaki, MD, $\mathrm{PhD}^{2}$ Kiminori Hosoda, MD, $\mathrm{PhD}^{1}$ and Nobuya Inagaki, MD, PhD ${ }^{2}$
}

\begin{abstract}
Background: Color affects emotions, feelings, and behaviors. We hypothesized that color used in selfmonitoring of blood glucose (SMBG) is helpful for patients to recognize and act on their glucose levels to improve glycemic control. Here, two color-indication methods, color record (CR) and color display (CD), were independently compared for their effects on glycemic control in less frequently insulin-treated type 2 diabetes.

Subjects and Methods: One hundred twenty outpatients were randomly allocated to four groups with $2 \times 2$ factorial design: $\mathrm{CR}$ or non-CR and $\mathrm{CD}$ or non-CD. Blood glucose levels were recorded in red or blue pencil in the CR arm, and a red or blue indicator light on the SMBG meter was lit in the CD arm, under hyperglycemia or hypoglycemia, respectively. The primary end point was difference in glycated hemoglobin (HbA1c) reduction in 24 weeks. Secondary end points were self-management performance change and psychological state change. Results: HbA1c levels at 24 weeks were significantly decreased in the CR arm by $-0.28 \%$ but were increased by $0.03 \%$ in the non-CR arm $(P=0.044)$. In addition, diet and exercise scores were significantly improved in the $\mathrm{CR}$ arm compared with the non-CR arm. The exercise score showed significant improvement in the CD arm compared with the non-CD arm but without a significant difference in HbAlc reduction. Changes in psychological states were not altered between the arms.

Conclusions: CR has a favorable effect on self-management performance without any influence on psychological stress, resulting in improved glycemic control in type 2 diabetes patients using less frequent insulin injection. Thus, active but not passive usage of color-indication methods by patients is important in successful SMBG.
\end{abstract}

\section{Background}

Alf-MONitoring OF BLOOD GLUCOSE (SMBG) provides $\checkmark$ an instrument for objective feedback on the impact of daily lifestyle habits, health conditions (e.g., illness, stress), and medications on glucose levels. It fosters self-management and empowers individuals to make beneficial changes in lifestyle. The American Diabetes Association recommends that SMBG be included in diabetes management and glycemic control for patients on multiple-dose insulin. ${ }^{1}$ On the other hand, there is no consensus on the utility of SMBG for glycemic control in diabetes patients using less frequent insulin injection because of controversial evidence from previous reviews. ${ }^{2-4}$

It is unclear why SMBG has no distinct effect on glycemic control for type 2 diabetes patients with less frequent insulin injection. However, a higher frequency of SMBG tests is

Departments of ${ }^{1}$ Human Health Science and ${ }^{2}$ Diabetes, Endocrinology and Nutrition, Graduate School of Medicine, Kyoto University, Kyoto, Japan.

${ }^{3}$ Department of Nursing, Graduate School of Medicine, Nagoya University, Nagoya, Japan.

This study has clinical trial registration number UMIN000006865 at www.umin.ac.jp

Parts of this study were presented at the $9^{\text {th }}$ International Diabetes Federation Western Pacific Region Congress and $4^{\text {th }}$ Scientific Meeting of the Asian Association for the Study of Diabetes, held in Kyoto, Japan, November 24-27, 2012, the 56 ${ }^{\text {th }}$ Annual Meeting of the Japan Diabetes Society, held in Kumamoto, Japan, May 16-18, 2013, the $49^{\text {th }}$ Annual Meeting of the European Association for the Study of Diabetes, held in Barcelona, Spain, September 23-27, 2013, and the World Diabetes Congress of the International Diabetes Federation, held in Melbourne, Australia, December 2-6, 2013. 
associated with improved glycemic control in patients with type 1 diabetes ${ }^{5}$ and also with type 2 diabetes. ${ }^{6}$ The low frequency of SMBG tests in patients using less frequent insulin injection might be a factor in the observed lack of improved glycemic control. SMBG is more helpful in diabetes management and glycemic control in conjunction with comprehensive self-care education, skills training, and ongoing support for patients. ${ }^{4,7}$ However, many patients, especially those with less frequent SMBG, take no action when their SMBG meter displays hyperglycemia or hypoglycemia. ${ }^{8}$ The unmet need of SMBG is to find a simpler, more efficient, and more economical method of promoting improvement in self-management and glycemic control.

To address this issue, we compared two separate colorindication methods: color record (CR) and color display (CD), both of which add color to emphasize high or low blood glucose levels in SMBG. Color is known to directly affect emotions, feelings, and behaviors in humans. It motivates different cognitive learnings: red produces avoidance motivation and enhances detail-oriented task; blue produces approach motivation and enhances creative task. ${ }^{9,10}$ We show here that $\mathrm{CR}$ has a favorable effect on self-management performance without any influence on psychological stress, resulting in improved glycemic control mostly due to an increase in motivation for exercise and diet.

\section{Research Design and Methods}

\section{Participants}

This study, called the Color IMPACT study (Color in SMBG Improves self-management Performance by Approaching Cognitive Transmission), is a prospective, randomized, controlled, single-center, open trial with a $2 \times 2$ factorial design to evaluate the effect of two color-indication methods used in SMBG-CR and CD—on glycemic control in type 2 diabetes patients. Outpatients at Kyoto University Hospital (Kyoto, Japan) were recruited. Inclusion criteria were type 2 diabetes with insulins, ongoing SMBG, age between 20 and 80 years old, glycated hemoglobin (HbA1c) levels between $7.0 \%$ and $10.5 \%$, and ability to diet and/or exercise. Exclusion criteria were diabetes duration of $<1$ year, initiation or treatment change with insulin or glucagonlike peptide-1 receptor agonists within 4 months, SMBG operated by other persons, severe comorbidities (e.g., severe cardiovascular disease, liver and renal disorders, malignancy), depression or psychiatric problems, impaired vision or synesthesia, abnormal hemoglobinemia, pregnancy, inability to follow trial procedures, or patients unsuitable for this study as judged by physicians. The study protocol was approved by the Institutional Review Board of Kyoto University Hospital (protocol number E1332) and is in compliance with the

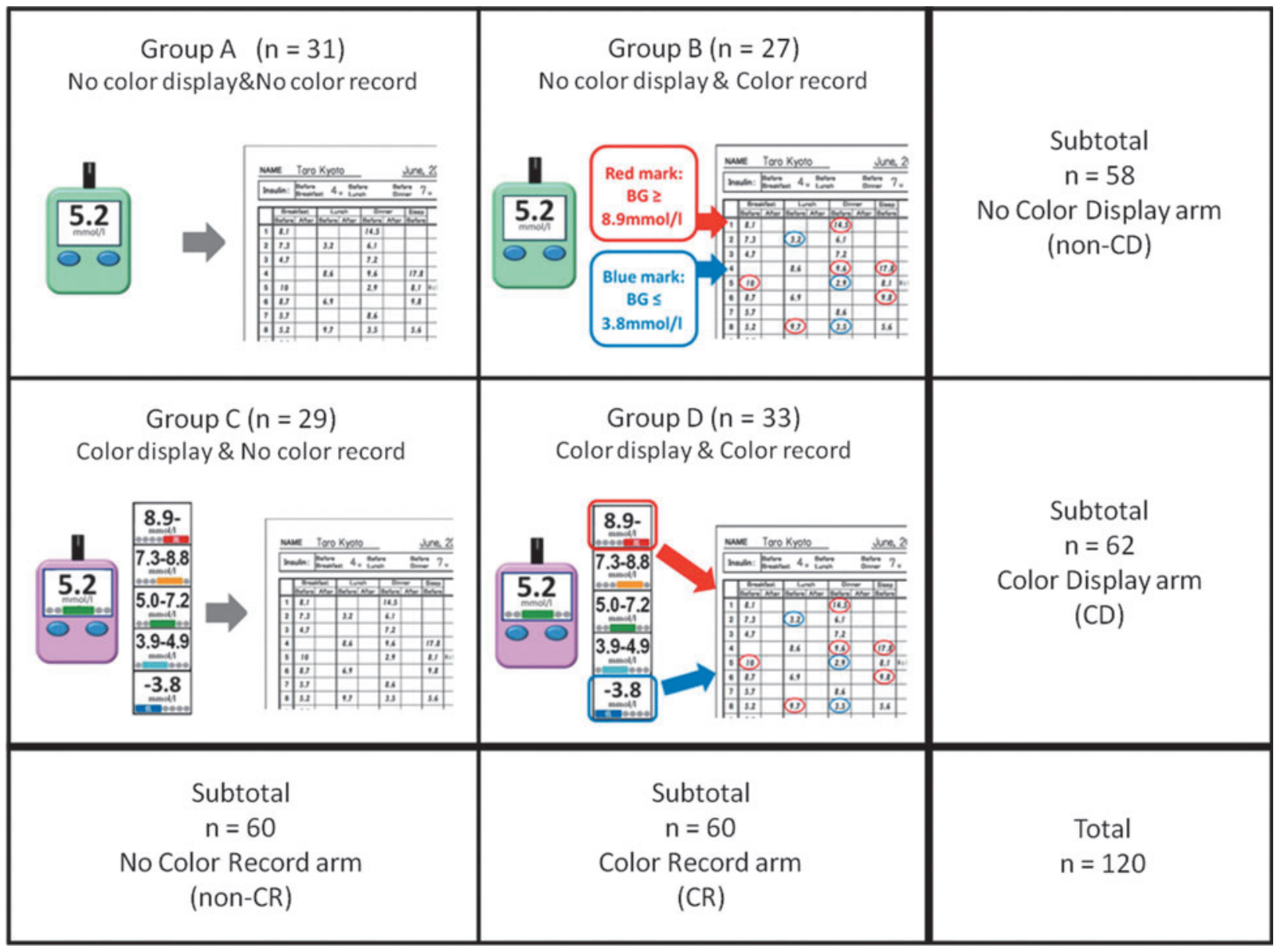

FIG. 1. The $2 \times 2$ factorial design and the number of subjects in each group and arm. BG, blood glucose. 
Helsinki Declaration. Written informed consent was obtained from all subjects.

\section{Procedures}

The study duration was 24 weeks. The subjects were assigned according to a $2 \times 2$ factorial design to one of four groups (Fig. 1): (A) no $\mathrm{CD}$ and no $\mathrm{CR}$ group, (B) no $\mathrm{CD}$ and CR group, (C) CD and no CR group, and (D) $\mathrm{CD}$ and $\mathrm{CR}$ group with a randomly generated allocation code using balanced design (age, gender, $\mathrm{HbA1c}$, diabetes duration, and the number of SMBG tests) in consecutively numbered sealed envelopes.

All of the subjects visited the hospital every 4 weeks, and laboratory data including $\mathrm{HbAlc}$, frequency of SMBG tests, and all documented medications were collected at $0,4,12$, and 24 weeks. Subjects completed a questionnaire on selfmanagement performance and psychological states at 0,4 , 12, and 24 weeks. Physicians-in-charge also filled in an original questionnaire about SMBG at 0 and 24 weeks.

Six diabetologists and three certified diabetes nurses participated in the study; the concepts and methods of the study were all learned in the same manner by all participants.

\section{Intervention}

All subjects were newly provided with a blood glucose meter (OneTouch ${ }^{\circledR}$ Ultra Vue $^{\mathrm{TM}}$; Johnson \& Johnson K.K., Tokyo, Japan) and instructed by one of the three nurses at enrollment. The subjects were requested to use the meter and record blood glucose levels manually in self-monitoring notes during the study.

The OneTouch Ultra Vue emphasizes blood glucose levels with five color-indicator lights (red, orange, green, light blue, and blue), which appear in a rectangle shape $(4.5 \mathrm{~mm}$ tall $\times$ $14.5 \mathrm{~mm}$ wide) under blood glucose value in black numbers ( $14 \mathrm{~mm}$ tall $\times 6-10 \mathrm{~mm}$ wide) on a display screen $(42 \mathrm{~mm}$ tall $\times 33 \mathrm{~mm}$ wide) with white background for $180 \mathrm{~s}$. In Groups $\mathrm{C}$ and $\mathrm{D}$, red, orange, green, light blue, and blue are shown when blood glucose levels are $\geq 8.9 \mathrm{mmol} / \mathrm{L}(160 \mathrm{mg} / \mathrm{dL})$, $7.3-8.8 \mathrm{mmol} / \mathrm{L} \quad(131-159 \mathrm{mg} / \mathrm{dL}), \quad 5.0-7.2 \mathrm{mmol} / \mathrm{L} \quad(90-$ $130 \mathrm{mg} / \mathrm{dL}), 3.9-4.9 \mathrm{mmol} / \mathrm{L}(71-89 \mathrm{mg} / \mathrm{dL})$, and $<3.8 \mathrm{mmol} /$ $\mathrm{L}(70 \mathrm{mg} / \mathrm{dL})$, respectively (CD arm) (Fig. 1). However, the indicator lights were turned off, and blood glucose levels were shown just in black on the meter for Groups A and B (non-CD arm).

Self-monitoring notes are provided by the Japan Association for Diabetes Education and Care and commonly used by patients to record blood glucose levels in Japan. In the study, subjects in Groups A and C recorded their blood glucose levels on the note manually in black pencil (non-CR arm). Groups B and $\mathrm{D}$ recorded their blood glucose levels in black and marked them with red or blue pencils when their glucose levels were $\geq 8.9 \mathrm{mmol} / \mathrm{L}(160 \mathrm{mg} / \mathrm{dL})$ or $<3.8 \mathrm{mmol} / \mathrm{L}(70 \mathrm{mg} / \mathrm{dL})$, respectively (CR arm) (Fig. 1).

\section{Measurements}

The primary end point was difference in $\mathrm{HbA} 1 \mathrm{c}$ reduction in 24 weeks between the $\mathrm{CR}(\mathrm{B}+\mathrm{D})$ and non-CR $(\mathrm{A}+\mathrm{C})$ arms and the $\mathrm{CD}(\mathrm{C}+\mathrm{D})$ and non- $\mathrm{CD}(\mathrm{A}+\mathrm{B})$ arms. The secondary end points were differences in self-management performance change and psychological state change and the difference in $\mathrm{HbA} 1 \mathrm{c}$ reduction in 24 weeks in treatmentunchanged subjects. Self-management performance was evaluated by the Summary of Diabetes Self-Care Activities Measure (SDSCA). ${ }^{11}$ The higher mean scores by subscales indicate the higher level of each self-care practice. Psychological states were measured using a validated, abridged version of Profile of Mood States (POMS). ${ }^{12}$ SDSCA was used to determine the effect of color on self-management performance, and POMS was performed because SMBG is reported to be associated with depression. ${ }^{13} \mathrm{We}$ also examined physicians' attitude to SMBG because lack of physicians' interest in the results of SMBG decreases motivation of patients. ${ }^{14}$ The original physician questionnaire consisted of four closed questions with a 5-point Likert scale from 0 ("not at all") to 4 ("extremely"): physician's satisfaction with the physician-patient relationship; sharing a common goal for glycemic control with patients; usefulness of SMBG for physicians in glycemic control; and usefulness of SMBG for patients in glycemic control. All questionnaires were administered by certified diabetes nurses.

\section{Statistical analysis}

To examine the primary end point, the independentsamples Student's $t$ test was used. The dependent-samples Student's $t$ test was used to compare the means of HbAlc levels between baseline and 24 weeks in the CR, non-CR, $\mathrm{CD}$, and non-CD arms. Similarly, the independent-samples Student's $t$ test was used to compare the change in the score on diet subscale of the SDSCA, the change in the score on all subscales of the POMS, and the change in HbA1c levels in 24 weeks in treatment-unchanged subjects. The MannWhitney nonparametric $U$ test was applied to compare change in the score on exercise and medications subscales of the SDSCA because these variables were not normally distributed. The $\chi^{2}$ test was used to compare the ratio of patients with improvements in the physician's questionnaire in 24 weeks. $P$ values of $<0.05$ were considered as statistically significant.

\section{Results}

\section{Subjects}

One hundred twenty subjects were enrolled in the study and randomized to one of four groups: Group A, $n=31$; Group B, $n=27$; Group C, $n=29$; and Group D, $n=33$. These four groups were structured for the factorial design: a non-CR arm consisting of Groups A and C; a CR arm consisting of Groups B and D; a non-CD arm consisting of Groups A and B; and a CD arm consisting of Groups $C$ and D (Fig. 1). The mean \pm SD age was $66.8 \pm 9.9$ years old, $40.6 \%$ of the subjects were female, the diabetes duration was $17.7 \pm 9.3$ years, the mean $\mathrm{HbAlc}$ level was $7.88 \pm 0.85 \%$, the SMBG frequency was $2.04 \pm 0.95$ times per day, and the frequency of insulin injection was $2.16 \pm 1.09$ times per day. There was no significant difference in demographic data of the subjects at the baseline among the four arms (Table 1). No significant differences were found in the socioeconomic status or levels of education between arms (data not shown). One hundred one of the 120 subjects $(84.2 \%)$ completed the study. Nine subjects (15.0\%) in the non-CR arm, 10 (16.7\%) in the CR arm, nine (15.5\%) in the non-CD arm, and 10 (16.1\%) in the CD arm were dropped because of hospitalization 
Table 1. Baseline Demographics for Study Subjects

\begin{tabular}{|c|c|c|c|c|c|c|}
\hline \multirow[b]{2}{*}{ Variable } & \multicolumn{3}{|c|}{ Assignment by $C R$} & \multicolumn{3}{|c|}{ Assignment by $C D$} \\
\hline & $C R(\mathrm{n}=60)$ & Non- $C R(\mathrm{n}=60)$ & $\mathrm{P}$ value & $C D(\mathrm{n}=62)$ & Non- $C D(\mathrm{n}=58)$ & $\mathrm{P}$ value \\
\hline Age (years) & $67.9 \pm 9.2$ & $66.0 \pm 1.4$ & 0.303 & $66.4 \pm 9.8$ & $67.5 \pm 10.7$ & 0.572 \\
\hline Female $(\%)$ & 41.7 & 40.0 & 0.853 & 43.5 & 37.9 & 0.532 \\
\hline Diabetes duration (years) & $17.0 \pm 8.7$ & $17.0 \pm 9.9$ & 0.984 & $17.9 \pm 10.2$ & $16.0 \pm 8.1$ & 0.280 \\
\hline HbAlc $(\%)$ & $7.87 \pm 0.81$ & $7.99 \pm 1.10$ & 0.521 & $7.97 \pm 0.99$ & $7.89 \pm 0.93$ & 0.658 \\
\hline SMBG frequency (times/day) & $2.28 \pm 1.21$ & $1.92 \pm 0.77$ & 0.059 & $2.21 \pm 1.16$ & $1.98 \pm 0.85$ & 0.227 \\
\hline
\end{tabular}

Data are mean \pm SD values.

$\mathrm{CD}$, color display; CR, color record; HbA1c, glycated hemoglobin; SMBG, self-monitoring of blood glucose.

for diabetes and comorbidities, with no significant difference among the arms.

\section{HbA1c findings}

HbA1c levels (mean \pm SE) were significantly decreased in the $\mathrm{CR}$ arm by $-0.28 \pm 0.12 \%$ (from $7.92 \pm 0.12 \%$ to $7.64 \pm 0.15 \%, P=0.018$ ) but were increased by $0.03 \pm 0.10 \%$ in the non-CR arm (from $7.84 \pm 0.12 \%$ to $7.87 \pm 0.16 \%$, $P=0.783$ ) at 24 weeks (Fig. 2A and C). The change in HbA1c levels in 24 weeks between the CR and non-CR arms was significantly $(P=0.044)$ different at $-0.31 \%(95 \%$ confidence interval, -0.61 to -0.01$)$. On the other hand, HbA1c levels were not significantly decreased, from $7.95 \pm 0.12 \%$ to $7.81 \pm 0.16 \% \quad(P=0.191)$ in the $\mathrm{CD}$ arm and from $7.81 \pm 0.12 \%$ to $7.70 \pm 0.15 \%(P=0.334)$ in the non-CD arm in 24 weeks (Fig. 2B). The change in HbA1c level in 24 weeks was $-0.14 \pm 0.10 \%$ in the CD arm and $-0.11 \pm 0.12 \%$ in the non-CD arm with no significant difference $(P=0.866)$ between the arms $(-0.03 \% ; 95 \%$ confidence interval, -0.33 to 0.28 ) (Fig. 2D). Correlation between change in HbA1c and the number of SMBG tests (times per day) was not found in the CR arm (Pearson's product-moment correlation coefficient $=-0.050, P=0.728$ ) (data not shown). The other factors such as age, sex, socioeconomic status, and education levels did not affect the difference in change in HbA1c between the $\mathrm{CR}$ and non-CR or the $\mathrm{CD}$ and non-CD arms.

Treatment-unchanged subjects also were analyzed for the effect of color on glycemic control. In these subjects, a significant change in HbA1c level at 24 weeks was observed in the CR arm compared with that in the non-CR arm $(-0.31 \pm 0.13 \%[P=0.021]$ vs. $0.04 \pm 0.11 \%[P=0.715])$ (Fig. $2 \mathrm{E})$. The difference in change in HbA1c level between the CR and non-CR arms was $-0.35 \%$ (95\% confidence interval, -0.69 to $-0.02 ; P=0.038)$. On the other hand, changes in HbA1c level in 24 weeks were $-0.28 \pm 0.13 \%$ in the CD arm $(P=0.037)$ and $0.00 \pm 0.11 \%$ in the non-CD arm $(P=0.981)$ (Fig. 2F). The apparent difference in change in HbA1c level between the arms was not significant $(-0.28 \%$; $95 \%$ confidence interval, -0.62 to $0.06 ; P=0.106)$.

\section{Self-management performance}

There were no statistically significant differences in the baseline scores on diet, exercise, and medication subscales of the SDSCA between the CR and non-CR arms and between the $\mathrm{CD}$ and non-CD arms (Table 2). Scores on the diet and exercise subscales of the SDSCA in 24 weeks were significantly increased in the $\mathrm{CR}$ arm compared with those in the
non-CR arm. The change in diet subscale score (mean $\pm \mathrm{SE}$ ) was $0.21 \pm 0.15$ points in the $C R$ arm and $-0.23 \pm 0.16$ points in the non-CR arm. The difference in change in diet scores between the $\mathrm{CR}$ and non-CR arms was 0.44 points (95\% confidence interval, 0.01 to $0.87 ; P=0.043$ ). Median change in exercise subscale score in 24 weeks was 0.50 (interquartile range, -1.00 to 1.00 ) points in the $\mathrm{CR}$ arm and 0.00 (interquartile range, -1.00 to 1.00 ) points in the non-CR arm with a significant difference between the arms $(P=0.045)$.

Median change in the score on exercise subscale in 24 weeks was 0.50 (interquartile range, -0.50 to 1.00 ) points in the $\mathrm{CD}$ arm and \pm 0.00 (interquartile range, -2.00 to +0.50 ) points in the non-CD arm. The difference between the arms was statistically significant $(P=0.045)$, but there were no significant differences in change in the scores of diet $(P=0.696)$ and medication $(P=0.095)$ subscales between arms. The change in medication subscale score was similar between each of the two arms (CD vs. non-CD, $P=0.095$; $C R$ vs. non-CR, $P=0.095$ ) (Table 2 ).

\section{Psychological states}

The baseline scores on all subscales of POMS in each arm were within the normal range. There were no significant differences in all subscale scores at baseline and at 24 weeks between the CR and non-CR arms and between the CD and non-CD arms (data not shown).

\section{Physicians' perspectives on SMBG}

There were no significant differences in all questions between each of the two arms at baseline. With regard to Question 2 (sharing a common goal for glycemic control with patients), the scores were improved at 24 weeks from baseline by $26.0 \%$ in the CR arm and by $9.8 \%$ in the non-CR arm with a significant difference between the arms $(P=0.033)$. However, a significant difference was not found between the CD arm (15.4\%) and the non-CD arm $(20.4 \%)$ $(P=0.510)$ (Table 2). There were no significant differences in the other three questions at 24 weeks between the two arms.

\section{Discussion}

The goal of the present study was to ascertain whether or not two color-indication methods used in SMBG-CR and $\mathrm{CD}$-improved glycemic control through an increase in selfmanagement performance in less frequently insulin-treated 

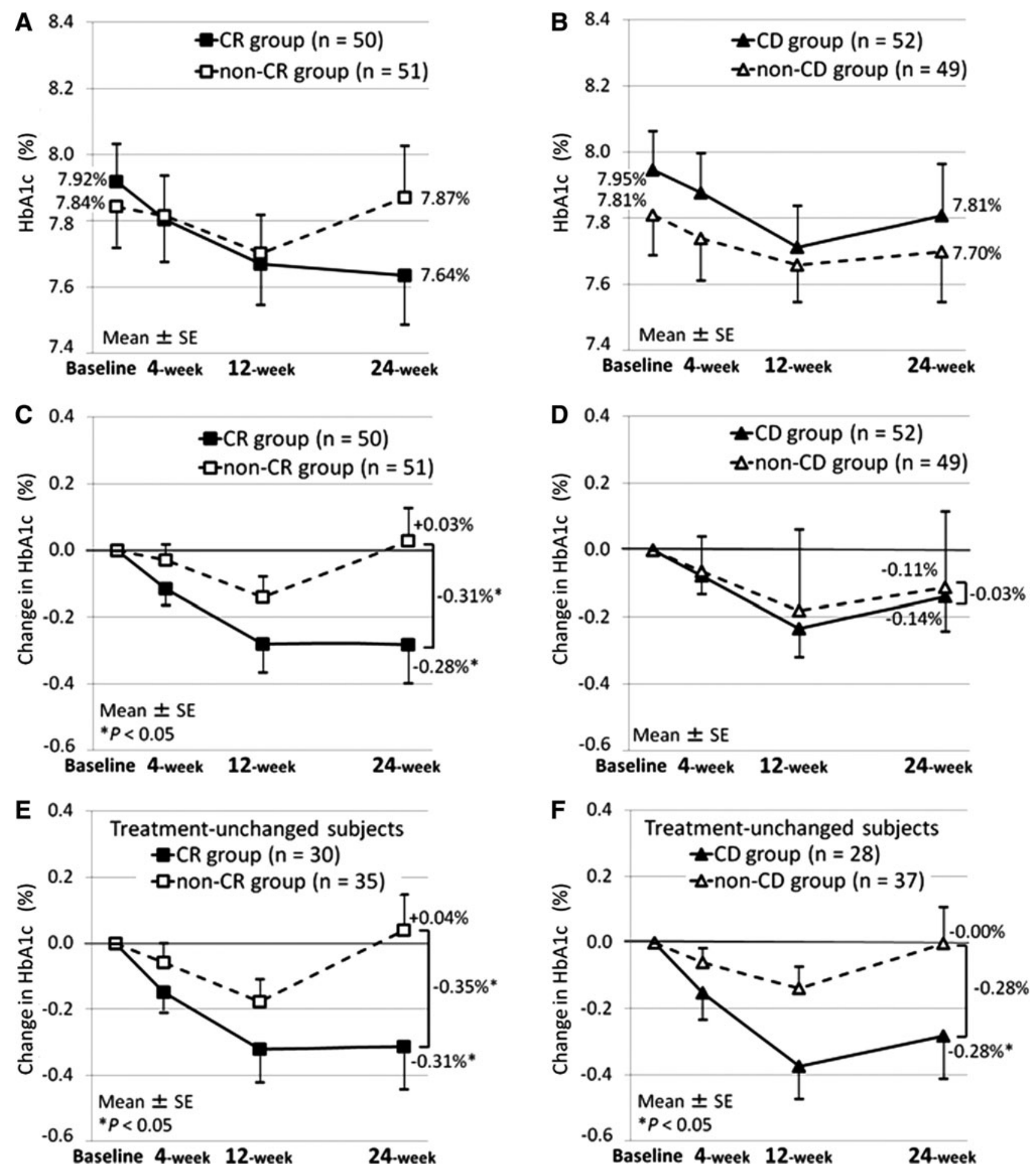

FIG. 2. Glycated hemoglobin (HbA1c) levels during the study. (A and B) HbA1c levels during a 24-week study period in (A) the color record (CR) and non-CR arms and the (B) color display (CD) and non-CD arms. (C and D) Change in HbA1c level during a 24-week study period in (C) the CR and non-CR arms and the (D) CD and non-CD arms. (E and F) Change in HbA1c level in the treatment-unchanged patients during a 24-week study period in (E) the CR and non-CR arms and (F) the CD and non-CD arms.

type 2 diabetes patients. We hypothesized that color-indication methods might motivate patients to recognize hyperglycemia and hypoglycemia and to begin problem-solving behavior. However, only CR has a favorable effect on glycemic control, through motivation to diet and exercise.
Correlation of change in HbAlc level and number of SMBG tests was not found in the CR arm. In addition, the number of SMBG tests was similar between the CR and CD arms. It is important in SMBG usage not to merely check blood glucose levels more frequently, but also to take action 
Table 2. Scores on the Summary of Diabetes Self-Care Activities Questionnaire and Change in the SCoRe of the Physician's Questionnaire in 24 WeEks

\begin{tabular}{|c|c|c|c|c|c|c|}
\hline \multirow[b]{2}{*}{ Variable } & \multicolumn{3}{|c|}{ Assignment by $C R$} & \multicolumn{3}{|c|}{ Assignment by $C D$} \\
\hline & $C R(\mathrm{n}=51)$ & Non-CR $(\mathrm{n}=50)$ & $\mathrm{P}$ value & $C D(\mathrm{n}=49)$ & Non- $C D(\mathrm{n}=52)$ & $\mathrm{P}$ value \\
\hline \multicolumn{7}{|l|}{ SDSCA } \\
\hline \multicolumn{7}{|l|}{ Diet } \\
\hline Baseline & $4.10 \pm 0.23$ & $4.32 \pm 0.18$ & 0.457 & $4.25 \pm 0.21$ & $4.18 \pm 0.20$ & 0.799 \\
\hline At 24 weeks & $4.32 \pm 0.20$ & $4.09 \pm 0.17$ & 0.393 & $4.20 \pm 0.19$ & $4.21 \pm 0.18$ & 0.964 \\
\hline Change in score & $0.21 \pm 0.15$ & $-0.23 \pm 0.16$ & $0.043^{\mathrm{a}}$ & $-0.05 \pm 0.15$ & $-0.03 \pm 0.16$ & 0.696 \\
\hline \multicolumn{7}{|l|}{ Exercise } \\
\hline Baseline & $2.75(2.88)$ & $4.00(3.50)$ & 0.097 & $2.75(2.88)$ & $4.00(3.25)$ & 0.062 \\
\hline At 24 weeks & $3.00(3.63)$ & $3.50(3.50)$ & 0.138 & $3.00(3.38)$ & $3.50(3.00)$ & 0.688 \\
\hline Change in score & $0.50(2.00)$ & $0.00(2.00)$ & $0.045^{\mathrm{a}}$ & $0.50(1.50)$ & $0.00(2.50)$ & $0.045^{\mathrm{a}}$ \\
\hline \multicolumn{7}{|l|}{ Medication } \\
\hline Baseline & $7.00(0.00)$ & $7.00(0.00)$ & 0.058 & $7.00(0.00)$ & $7.00(0.00)$ & 0.723 \\
\hline At 24 weeks & $7.00(0.00)$ & $7.00(0.00)$ & 0.436 & $7.00(0.00)$ & $7.00(0.00)$ & 0.379 \\
\hline Change in score & $0.00(0.00)$ & $0.00(0.00)$ & 0.095 & $0.00(0.00)$ & $0.00(0.00)$ & 0.095 \\
\hline \multicolumn{7}{|l|}{ Physician's questionnaire ${ }^{\mathrm{b}}$} \\
\hline Question 1: Physician satisfaction? & & & 0.215 & & & 0.689 \\
\hline Increase & $14(28.0)$ & 9 (17.6) & & $11(21.2)$ & $12(24.5)$ & \\
\hline No increase & $36(72.0)$ & $42(82.4)$ & & $41(78.8)$ & $37(75.5)$ & \\
\hline Question 2: Shared goal? & & & $0.033^{\mathrm{a}}$ & & & 0.510 \\
\hline Increase & $13(26.0)$ & $5(9.8)$ & & $8(15.4)$ & $10(20.4)$ & \\
\hline No increase & $37(74.0)$ & $46(90.2)$ & & 44 (84.6) & 39 (79.6) & \\
\hline Question 3: Usefulness for physician? & & & 0.231 & & & 0.203 \\
\hline Increase & $9(18.0)$ & $5(9.8)$ & & $5(9.6)$ & $9(18.4)$ & \\
\hline No increase & $41(82.0)$ & $46(90.2)$ & & $47(90.4)$ & 40 (81.6) & \\
\hline Question 4: Usefulness for patient? & & & 0.778 & & & 0.674 \\
\hline Increase & $17(34.0)$ & $16(31.4)$ & & $16(30.8)$ & $17(34.7)$ & \\
\hline No increase & $33(66.0)$ & 35 (68.6) & & $36(69.2)$ & $32(65.3)$ & \\
\hline
\end{tabular}

Diet data are mean \pm SE values. Exercise and medication data are median (interquartile range) values. Values for the physician's questionnaire are number (percentages).

${ }^{\mathrm{a}} P<0.05$ was considered to indicate a significant difference.

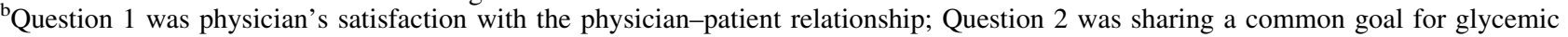
control with patients; Question 3 was usefulness of self-monitoring of blood glucose for the physician in glycemic control; and Question 4 was usefulness of self-monitoring of blood glucose for the patient in glycemic control.

CD, color display; CR, color record; SDSCA, Summary of Diabetes Self-Care Activities Measure.

on the findings. Recording their blood glucose levels in blue or red can facilitate patients' change of behavior, as motivation to diet and exercise was increased during the study. On the other hand, although motivation to exercise was increased, glycemic control was not improved in the CD arm. Even though hyperglycemia and hypoglycemia are emphasized on the SMBG meter in the $\mathrm{CD}$ arm, the information did not always cause behavioral changes. These results suggest that active but not passive usage is important in successful SMBG.

Action by patients is a key to improve glycemic control in type 2 diabetes treated less frequently with insulin injection. SMBG is recognized as one tool for such self-management. However, it has been reported that many patients often do nothing when blood glucose levels are high or low when using the existing noncolor method of SMBG. ${ }^{8}$ Furthermore, physicians' lack of interest in the results of SMBG decreases motivation of patients. ${ }^{14}$ However, in our study, sharing a common goal for glycemic control was increased in the CR arm compared with the non-CR arm, indicating that $\mathrm{CR}$ in SMBG can be beneficial in promoting mutual understanding and partnership between patients and healthcare professionals. As a result, self-management performance and HbA1c levels were improved in the CR arm not only of all subjects but also of treatment-unchanged subjects.
Change in psychological states was not observed in either arm of the present study. The ESMON study showed that SMBG was associated with higher scores on depression when newly diagnosed diabetes patients were reviewed by healthcare professionals at a long-term interval ( 3 months). ${ }^{13}$ On the other hand, SMBG with adjuvant counseling at 0, 4, 12, and 20 weeks resulted in improvements for general well-being and depression. $^{15}$ In our study, all subjects were reviewed by nurses at $0,4,12$, and 24 weeks in addition to regular monthly assessment by physicians. All subjects were free to ask the nurse's advice at any time. Reassurance is a key for continued self-monitoring. ${ }^{14}$ Subjects in our study showed a sense of reassurance and were not distressed by poor results of SMBG.

The potential weakness of this study is that this was a single-center trial and that the sample size is too small to determine whether the combination of $\mathrm{CR}$ and $\mathrm{CD}$ is more effective for glycemic control than $\mathrm{CR}$ alone. However, subanalysis suggested that $\mathrm{CR}$ alone has a more favorable effect on glycemic control compared with combination of CR and CD (data not shown), implying that too much information for patients may not necessarily improve motivation to life-style modification and glycemic control. Further studies are needed to clarify which patients are more likely to benefit from $\mathrm{CR}, \mathrm{CD}$, and other methods of SMBG. 
In summary, CR has a favorable effect on self-management performance without any influence on psychological stress and results in improved glycemic control in less frequently insulintreated type 2 diabetes patients. Our results indicate that providing medical care and educational aid are not always helpful for self-management; however, this might not be limited to SMBG usage. Maintenance of a balance of intervention between patients and healthcare professionals is important for optimized self-management.

\section{Author Disclosure Statement}

No competing financial interests exist. The study conception and protocol were performed by A.N., S.H., I.H., K.H., and N.I. Subject training was performed by A.N., I.H., and Y.S. Statistical analysis was performed by N.H., K.N., and A.H. Manuscript development was performed by A.N., S.H., I.H., K.H., and N.I.

\section{References}

1. American Diabetes Association: Standards of medical care in diabetes-2013. Diabetes Care 2013;36(Suppl 1):S11S66.

2. Clar C, Barnard K, Cummins E, Royle P, Waugh N; Aberdeen Health Technology Assessment Group: Selfmonitoring of blood glucose in type 2 diabetes: systematic review. Health Technol Assess 2010;14:1-140.

3. Balk E, Teplinsky E, Trikalinos T, Chew P, Chung M, Lau J, Pittas A: Applicability of the Evidence Regarding Intensive Glycemic Control and Self-Monitored Blood Glucose to Medicare Patients with Type 2 Diabetes. Technology Assessment Report. Rockville, MD: Agency for Healthcare Research and Quality, 2007:83.

4. Jansen JP: Self-monitoring of glucose in type 2 diabetes mellitus: a Bayesian meta-analysis of direct and indirect comparisons. Curr Med Res Opin 2006;22:671-681.

5. Miller KM, Beck RW, Bergenstal RM, Goland RS, Haller MJ, McGill JB, Rodriguez H, Simmons JH, Hirsch IB; T1D Exchange Clinic Network: Evidence of a strong association between frequency of self-monitoring of blood glucose and hemoglobin A1c levels in T1D Exchange Clinic Registry participants. Diabetes Care 2013;36:2009-2014.

6. Harashima S, Fukushima T, Sasaki M, Nishi Y, Fujimoto S, Ogura M, Yamane S, Tanaka D, Harada N, Hamasaki A, Nagashima K, Nakahigashi Y, Seino Y, Inagaki N: Selfmonitoring of blood glucose (SMBG) improves glycaemic control in oral hypoglycaemic agent (OHA)-treated type 2 diabetes (SMBG-OHA study). Diabetes Metab Res Rev 2013;29:77-84.

7. Cho JH, Chang SA, Kwon HS, Choi YH, Ko SH, Moon SD, Yoo SJ, Song KH, Son HS, Kim HS, Lee WC, Cha BY, Son HY, Yoon KH: Long-term effect of the internet-based glucose monitoring system on $\mathrm{HbAlc}$ reduction and glucose stability: a 30-month follow-up study for diabetes management with a ubiquitous medical care system. Diabetes Care 2006;29:2625-2631.

8. Wang J, Zgibor J, Matthews JT, Charron-Prochownik D, Sereika SM, Siminerio L: Self-monitoring of blood glucose is associated with problem-solving skills in hyperglycemia and hypoglycemia. Diabetes Educ 2012;38:207-214.

9. Elliot AJ, Maier MA, Moller AC, Friedman R, Meinhardt J: Color and psychological functioning: the effect of red on performance attainment. J Exp Psychol Gen 2007;136:154168.

10. Mehta R, Zhu R: Blue or red? Exploring the effect of color on cognitive task performances. Science 2009;323:12261229.

11. Toobert DJ, Hampson SE, Glasgow RE: The summary of diabetes Self-Care Activities Measure: results from 7 studies and a revised scale. Diabetes Care 2000;23:943-950.

12. McNair DM, Lorr M, Droppleman LF: Manual for the Profile of Mood States (POMS), Revised. San Diego, CA: Educational and Industrial Testing Service, 1992.

13. O'Kane MJ, Bunting B, Copeland M, Coates VE; ESMON Study Group: Efficacy of self monitoring of blood glucose in patients with newly diagnosed type 2 diabetes (ESMON Study): randomised controlled trial. BMJ 2008;336:11741177.

14. Peel E, Douglas M, Lawton J: Self monitoring of blood glucose in type 2 diabetes: longitudinal qualitative study of patients' perspectives. BMJ 2007;335:493-498.

15. Schwedes U, Siebolds M, Mertes G; SMBG Study Group: Meal-related structured self-monitoring of blood glucose: effect on diabetes control in non-insulin-treated type 2 diabetic patients. Diabetes Care 2002;25:1928-1932.

Address correspondence to: Shin-ichi Harashima, MD, PhD

Department of Diabetes, Endocrinology and Nutrition Graduate School of Medicine Kyoto University

54 Shogoin Kawahara-cho Sakyo-ku, Kyoto-city, Kyoto 606-8507, Japan E-mail: harasima@metab.kuhp.kyoto-u.ac.jp 